\title{
Harnessing history: Highlighting CHLA / ABSC capacity building through the Northern Alberta Health Libraries Association (NAHLA), 1985-2007
}

\author{
Trish Chatterley, Marlene Dorgan, Connie Clifford, Liza Chan, \\ Janice Varney, and Orvie Dingwall
}

\begin{abstract}
Objective - The purpose of the Northern Alberta Health Libraries Association (NAHLA) History Project was to capture, collect, and document the history of NAHLA, record and share the process with other Canadian Health Libraries Association / Association des bibliothèques de la santé du Canada (CHLA / ABSC) chapters, and systematically organize NAHLA documents for delivery to the Provincial Archives of Alberta. Methods - The methodology employed for this project is described in detail in the CHLA / ABSC Fact Sheet "Reporting Your Chapter History: The Process", available at the CHLA/ABSC Web site (http://www.chla-absc.ca). Results - During the course of the project, the History Group uncovered the very active and successful 23-year history of NAHLA. The History Group captured the story of the chapter's origins, identified political actions and educational offerings, and learned of members' perspectives about what NAHLA meant to them personally and professionally. Reviewing the Association chronology revealed changes in the focus of NAHLA over the years; those trends are also discussed. Discussion - The process of compiling and documenting a local association history can be a rewarding and enlightening experience. It leads to the long term preservation of knowledge of the association's origins and development. The authors hope the present article will inspire other chapters to initiate similar projects to preserve their own local histories.
\end{abstract}

\section{Introduction}

In 1998, the Canadian Health Libraries Association / Association des bibliothèques de la santé du Canada (CHLA / ABSC) launched its Oral History Program in an attempt to preserve the recollections of its founding and early members. The Oral History Committee encouraged regional chapters to do the same. In 2004, the Northern Alberta Health Libraries Association (NAHLA) was successful in its application for a Chapter Initiatives Grant from CHLA / ABSC to form its own Oral History Group. Since the project's outset, the focus has shifted from oral history in particular to history in general. The group was renamed the NAHLA History Group and its terms of reference were modified to include a comprehensive review of the documented history of NAHLA in addition to the collection of oral remembrances.

\section{NAHLA origins and official CHLA / ABSC chapter status}

An informal group of librarians known as the Edmonton Health Libraries Group met periodically in the early 1980s to discuss issues of influence on their various professional responsibilities. Under the direction of Donna Dryden, this group sought official chapter status from CHLA / ABSC. In January 1985, 1 month before its official member status was granted, NAHLA held its inaugural meeting. An executive was established with Donna Dryden as the first president. The original bylaws stated that NAHLA's objective would be "to provide professional support and fellowship to the membership and to foster quality health information services in northern Alberta".

T. Chatterley. ${ }^{1}$ John W. Scott Health Sciences Library, University of Alberta, Edmonton, AB T6G 2R7, Canada; and Institute of Health Economics, 1200-10405 Jasper Avenue, Edmonton, AB T5J 3N4, Canada.

M. Dorgan. John W. Scott Health Sciences Library, University of Alberta, Edmonton, AB T6G 2R7, Canada.

C. Clifford. Caritas Health Group, Learning Resources, 1100 Youville Drive West, Edmonton, AB T6L 5X8, Canada.

L. Chan. John W. Scott Health Sciences Library, University of Alberta, Edmonton, AB T6G 2R7, Canada; and Alberta Heritage Foundation for Medical Research, Suite 1500, 10104-103 Avenue, Edmonton, AB T5J 4A7, Canada.

J. Varney. Current affiliation not available.

O. Dingwall. Canadian Patient Safety Institute, Suite 1414, 10235-101 Street, Edmonton, AB T5J 3G1, Canada.

${ }^{1}$ Corresponding author (e-mail: patricia.chatterley@ualberta.ca). 


\section{Advocacy}

During the Association's early years, NAHLA members focused their attention on provincial and national politics and became vocal advocates where health issues were concerned. In 1988, Association members were encouraged to write to their local members of Parliament regarding Copyright Bill C-60 and its effect on access to health information. That same year, a brief titled "Information: a priceless and cost-effective resource" was submitted in response to the Premier's Commission on the Future of Health Care for Albertans. This NAHLA document highlighted the important role of libraries in the delivery of efficient and effective health care. Shortly thereafter, in March 1990, NAHLA hosted a forum to discuss the future of Alberta's health care system, inviting MLA representatives from each of the three legislative parties to comment on the then recently published Rainbow Report [1]. The Rainbow Report summarized the conclusions and recommendations arising from the Premier's Commission on the Future of Health Care for Albertans.

\section{Creation of the Hospital Library Group}

In the early 1990s, hospital librarians working in Edmonton felt a sense of isolation in their positions. Contact with other NAHLA colleagues helped to ease this isolation, but only three or four NAHLA meetings were held each year. There was a need for an informal but frequent forum to discuss matters of mutual interest and concern. In response to this need, the Hospital Library Group was formed in 1990 as a subgroup of NAHLA. In 1993 this group won the CHLA / ABSC 10th Anniversary Commemorative Award for its "cooperative spirit". Still active, the Group's objectives are to encourage ongoing communication among members, to offer a forum for the exchange of information between the Group and the John W. Scott Health Sciences Library, University of Alberta, and to continue to foster mutually beneficial services for all concerned.

\section{Education}

Local initiatives and the restructuring of the provincial health care system had a direct impact on health science librarianship in northern Alberta during the mid-1990s. Many hospital and health association libraries were closed, reducing the number of career opportunities for health science librarians in the province. The impact was felt by NAHLA as the membership that originally included representatives from such northern cities as Fort McMurray, Grande Prairie, and Yellowknife was reduced to a more local, Edmonton-based group.

During this time, NAHLA's focus shifted from political advocacy towards professional development, as reflected by the increase in the number of educational activities offered by NAHLA to its members and to the broader library community. The Association hosted guest lecturers and offered events that included technology training sessions and workshops on conducting systematic reviews. In 2002, NAHLA's Executive organized the first TRENDS (Teaching, Research, Education, 'Nowledge, Direction, Strength) Miniconference. An annual event, the TRENDS conference offers an affordable educational program for all local librarians. In addition to presentations by key players in health research and (or) health librarianship, lectures are offered on such topics as management, evidence-based librarianship, and grant writing. As a result, the symposium appeals to a wide and diverse audience.

In 2005, NAHLA began sponsoring a series of Leading Edge workshops. These interactive sessions teach local librarians practical applications for the daily operations and services of health sciences libraries. These workshops have contributed significantly to local librarians' understanding and application of electronic health resources and research practices.

Over the years the NAHLA Executive has enlisted a wide range of guest speakers to present on health-related topics. One notable invitee was Babs Flower, a name familiar to many health librarians. In February 1987 she spoke to the NAHLA membership about the results of her Association of Canadian Medical Colleges/Canadian Health Libraries Association survey project on health science collections and library services in Canada [2]. Presenters at other NAHLA events have included local professionals, but some have come from further afield. For example, Raisa Pavlenko, Director of the State Scientific Library of Ukraine, spoke to the membership in 1995, and in 2003 Terena Solomons from the Hollywood Private Hospital in Perth, Australia, shared her experiences related to health library services.

\section{Special projects}

NAHLA members have been actively involved in several special projects since the Association's beginning. One year after becoming an official CHLA / ABSC chapter, NAHLA published its first Union List of Serials of the Northern Alberta Health Libraries Association [3]. This resource was important to local libraries as it facilitated resource sharing, a service that remains relevant to this day. During the next 10 years, four more editions of the Union List were published before the print resource was converted to an online format in SERHOLD for more widespread use.

In 1988, just 3 years after its establishment, NAHLA undertook the planning and organization of the 1990 CHLA / ABSC Annual Conference. Though still a young association, NAHLA was able to recruit enough interested members to host a very successful conference titled "Health Information for All". NAHLA organized the conference a second time in 2003; the theme was the "Information Mosaic: Bringing the Pieces Together". The conference was avidly promoted by mascot Ed Montosaurus, who is still active in the local association. Ed made friends with the 2008 Conference mascot, Norman Scotia, on his recent visit to Edmonton.

In 1995, the Consumer Health Information Working Group was established with the mandate to develop a directory of consumer health information resources and services available in the Edmonton region [4]. Funded by a CHLA / ABSC Development Award, the directory was published in 1997 and updated in 2000. Since that time, an increase in access to relevant consumer health Web sites reduced the necessity for new print editions of the directory, and work on it subsequently ceased. 
This History Project generated end-products that are expanding NAHLA's scope and building its capacity further afield. Developing a process to deposit the Association's documents in the Provincial Archives of Alberta creates an official historical record of NAHLA and its impact on northern Alberta. The Fact Sheet outlining history compilation procedures and guidelines may encourage other CHLA / ABSC chapters to initiate similar projects to preserve their own local histories.

\section{Involvement in the local library community}

For the past 15 years, NAHLA members have supported the local library community in many ways. In 1992, NAHLA members participated in a meeting with seven other Edmonton library groups to discuss a joint committee on staff development. Members mentor future information specialists by participating in the University of Alberta, School of Library and Information Studies (SLIS) Partners' Week, which provides an opportunity for current students to job shadow professional librarians for a day. NAHLA provides financial support to Partners' Week and the SLIS Professional Development Day, a free daylong conference for SLIS students and Edmonton area librarians. NAHLA also provided financial support for the 2001 Canadian Cochrane Symposium, which was held in Edmonton. In April of this year (2008), in collaboration with the Southern Alberta Health Libraries Association (SAHLA) and the Health Knowledge Network (HKN), NAHLA co-hosted a daylong symposium titled "Evidence in Complementary Medicine: Getting It Right”.

\section{Benefits of NAHLA membership}

As an organization, NAHLA has always been a very small and cohesive group. Local health science librarians are "almost" obligated to belong to NAHLA, and new librarians are strongly encouraged to join. Membership has brought many benefits, as reflected in comments by our focus group participants. In the early days of NAHLA, membership enabled them "to keep in touch with what was happening politically" and to keep "up-to-date with the broad field of health sciences, not necessarily specific to libraries or even health sciences, but with what was helpful to know in a working environment". Later, members focused on the networking and training opportunities that became available to them.

For solo librarians, NAHLA facilitated connections with others in similar positions and enabled individuals to "capitali[ze] on all of the expertise in health librarianship in Edmonton", as stated by one of the focus group participants. Membership offered "a way to get to know other health librarians who [they] spoke on the phone with a lot during the day". For many, membership encouraged relationships beyond their home institution and in diverse employment sectors, making them feel like part of a larger group of colleagues. Librarians from academic, government, hospital, corporate, and public library environments shared their experiences and learned about what was happening in the various milieus. With the current focus on educational activities that offer professional development opportunities to members, there is a sense of community within NAHLA. For those who have served on the NAHLA Executive "that experience of being on an Executive, learning how to chair meetings in a nonthreatening environment, and the opportunity to learn the different roles of the Treasurer, President, etc." served as a stepping stone for building the confidence and expertise needed to serve on national committees.

\section{Governance}

NAHLA's Executive has continued to keep pace with changing times and environments, amending the Association's policies as needed. In 2005 an Executive Handbook was created to systematize the functioning of the Association. A recent addition to the handbook was a disposition schedule that outlines the protocols for retention, organization, and deposit of Association records to the Provincial Archives of Alberta. In 2006 the NAHLA membership approved the current NAHLA mission statement, "empowering health information specialists in Northern Alberta to support health care and research, through leadership, networking, and education". The most recent amendment to the Association bylaws, approved in 2007, was the inclusion of a dissolution clause in reaction to the disbanding of a CHLA / ABSC chapter in Ontario in 2006.

\section{CHLA / ABSC and NAHLA}

CHLA / ABSC financial support has been invaluable to NAHLA throughout its history. Without financial resources provided through such grant programs as the CHLA Chapter Initiatives Fund, several of NAHLA's larger-scale projects could not have been accomplished. Grant money was used to fund the conversion of NAHLA's Union List holdings into SERHOLD, to produce the Edmonton Consumer Health Information Directory, and to enable the NAHLA History Group to undertake the project as described above. Other funds supported such programs as the 1997 MLA satellite conference on the "Future of Librarianship" and the 1998 workshop, "EBM for Librarians: Panning for Gold", coorganized with the Southern Alberta Health Library Association and taught by Cindy Walker-Dilks from McMaster University.

Over the years, NAHLA members have been involved and continue to be active participants in the operation of CHLA / ABSC. Linda Slater, Lea Starr, and Donna Dryden have all served as presidents of CHLA, in addition to other involvement as CHLA / ABSC directors. Connie Clifford, Linda Slater, Jeannette Smit, and Lea Starr served on national committees: the Task Force on Hospital Library Standards, liaison to the National Network of Libraries for Health, the Volunteer Task Force, and the Task Force on Resource Sharing, respectively. Ellen Crumley, Richard Thornley, Sandra Shores, and Peter Schoenberg have served as either assistant editor or editor of BMC/JCHLA.

\section{Social events}

No association history would be complete without a record of its social gatherings. During the History Group's focus group sessions, some of the strongest recollections were of the food that was offered at various events! During its for- 
mative years, NAHLA hosted an annual summer social for members. In 1999, the timing of the Annual General Meeting was changed from spring to fall, and the NAHLA Executive began the tradition of sponsoring the dinner that followed ("we're all about open access!"). The combination of a business meeting followed by food and conversation makes for an enjoyable evening and attendance is always high. The professional nature of the meeting is maintained by the atmosphere of the Corbett Hall Boardroom at the University of Alberta, where the AGM has been held since 1994. Prior to that date, it had been held in members' homes or in restaurants.

An annual Christmas luncheon has been held since the establishment of NAHLA. Initially, these luncheons were held in members' homes but were eventually relocated to Edmonton restaurants. For many years the lunches have also been accompanied by a "re-gift" exchange. Attendees bring a gift that they have received on a previous occasion and draw for the re-gifted present that they are fortunate (or unfortunate) enough to receive. There is always a danger of ending up with the Christmas candles that seem to be recycled every year!

\section{Discussion and conclusion}

NAHLA's 23-year history has been very active and successful. The Association has progressed from a small, politically active group to a (still) small but energetic CHLA / ABSC chapter. NAHLA's current focus is on empowering health information specialists in northern Alberta to support health care services and research, through leadership, advocacy, networking and education. By offering affordable professional development and networking opportunities for health information specialists, NAHLA encourages professional and personal growth, collaboration, generosity, companionship, and camaraderie within the health library community.

Articulating the history of NAHLA has been a rewarding and enlightening experience not only for NAHLA History
Group members, but more importantly, for the Chapter itself. The authors hope that the poster presentation at the CHLA / ABSC Conference in 2007, the "Reporting Your Chapter History: the Process" Fact Sheet and this article will increase awareness about the importance of preserving local chapter history and will encourage and assist other chapters to initiate similar projects [5].

\section{Acknowledgements}

NAHLA's History Group would like to thank the many individuals who submitted Association documents and who shared their stories. Without them, this project would not have been possible. If reading this article has sparked special memories about NAHLA or NAHLA members, please share them by e-mailing comments and thoughts to nahla@nahla.ca.

\section{References}

1. Alberta Health. Partners in Health : the Government of Alberta's response to the Premier's Commission on Future Health Care for Albertans. Edmonton: Communications Branch, Alberta Health; 1991.

2. Flower MA. Libraries Without Walls: Blueprint for the Future. Toronto: Association of Canadian Medical Colleges, Canadian Health Libraries Association; 1987.

3. Northern Alberta Health Libraries Association. Union List of Serials of the Northern Alberta Health Libraries Association. Toronto: McAinsh \& Co.; 1986.

4. Northern Alberta Health Libraries Association. Consumer health information: a directory of resources in Edmonton and area. Edmonton: Northern Alberta Health Libraries Association; 1996.

5. Dorgan M, Chan L, Chatterley T, Clifford C, Dingwall O, Varney J. Reporting Your Chapter History: the Process. Canadian Health Libraries Association Factsheet [monograph on the Internet]. Edmonton: Northern Alberta Health Libraries Association; 2007 [cited 2008 Mar 25]. Available from http://www.chla-absc.ca/?q=en/node/107. 
This article has been cited by:

1. C. Shaw-Daigle, L. Demczuk, A. Osterreicher, M. Raynard. 2011. A look back on the Prairie: the Manitoba Health Libraries Association / Manitoba Association of Health Information Providers (MHLA / MAHIP) chapter history project. Journal of the Canadian Health Libraries Association 32:1, 17-19. [Citation] [PDF] [PDF Plus]

2. 2011. Full Issue in PDF / Numéro complet enform PDF. Journal of the Canadian Health Libraries Association 32:1, 1-45. [Citation] [PDF] [PDF Plus] 